DIW BERLIN

Discussion

Papers
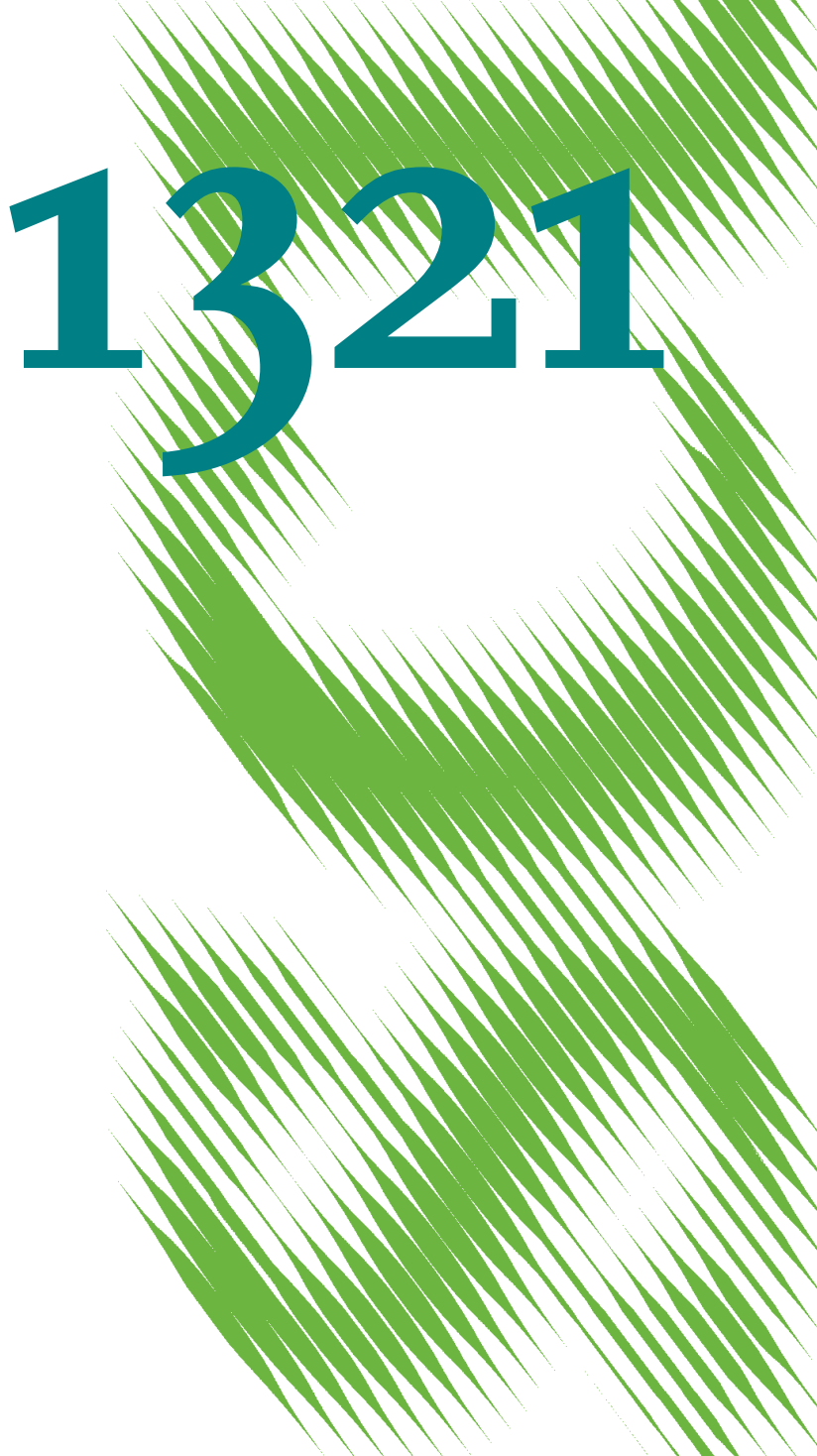

Merger Externalities in

Oligopolistic Markets 
Opinions expressed in this paper are those of the author(s) and do not necessarily reflect views of the institute.

IMPRESSUM

(C) DIW Berlin, 2013

DIW Berlin

German Institute for Economic Research

Mohrenstr. 58

10117 Berlin

Tel. $+49(30) 89789-0$

Fax +49 (30) $89789-200$

http://www.diw.de

ISSN print edition $1433-0210$

ISSN electronic edition 1619-4535

Papers can be downloaded free of charge from the DIW Berlin website:

http://www.diw.de/discussionpapers

Discussion Papers of DIW Berlin are indexed in RePEc and SSRN:

http://ideas.repec.org/s/diw/diwwpp.html

http://www.ssrn.com/link/DIW-Berlin-German-Inst-Econ-Res.html 


\title{
Merger externalities in oligopolistic markets
}

\author{
Klaus Gugler and Florian Szüics*
}

June 2013

\begin{abstract}
We quantify externalities on profitability and market shares of competing firms in oligopolistic markets through the transition from an $n$ to an $n-1$ player oligopoly after a merger. Competitors are identified via the European Commission's market investigations and our methodology allows us to distinguish the externality due to the change in market structure from the merger effect. We obtain results consistent with the predictions of standard oligopoly models: rivals expand their output and increase their profits, whereas merging firms are negatively affected. This indicates that on average the market power effects of large mergers outweigh the efficiencies. (JEL L13, L40, G34)
\end{abstract}

\section{Introduction}

In markets characterized by oligopolistic competition a merger imposes two externalities on non-merging, rival firms: a positive externality due to the reduction of the number of competitors (the market power effect) and a negative externality due to the optimal reallocation of the merging firms' productive assets (the efficiency effect). The net externality of the merger on the market depends on the relative strenght of these two antipodal forces in the specific merger, but standard oligopoly models suggest a positive net effect: under quantity competition or price competition with differentiated goods, the merged entity finds it - absent substantial efficiency gains - optimal to reduce its production (Farrell and Shapiro, 1990; Deneckere and Davidson, 1985). In the new equilibrium the rivals sell a higher quantity at a higher price, which is clearly profitable, while the effect on merging firms is ambiguous at best. The result that mergers supposedly benefit outsiders more than insiders is often called the merger paradox.

The fact that this puzzling prediction of standard oligopoly models has not - as far as we know - been empirically explored can be explained by a number of conceptual and practical issues, such as the definition of the relevant market and the construction of a valid counterfactual. Specifically, since oligopolies in which a merger would cause a sizeable externality would typically consist of only a few firms, ${ }^{1}$ measurement depends crucially on the correct identification of the affected firms, that is, the assessment of the relevant market. Gross approximations, say industry codes, would be insufficient, as the inclusion of unaffected firms would bias the results toward zero.

*Gugler: WU (Vienna University of Economics and Business), Augasse 2-6, 1090 Vienna, Austria. E-mail: klaus.gugler@wu.ac.at; Szücs: DIW Berlin, Mohrenstr. 58, 10117 Berlin, Germany. E-mail: fszuecs@diw.de. The authors would like to thank Tomaso Duso, Robert Feinberg and the participants of RNIC 2012 (Vienna) and IIOC 2013 (Boston) for helpful comments.

${ }^{1}$ All standard models predict that for a large number of firms the oligopolistic equilibrium moves toward the competitive equilibrium, reducing the importance of the merger externalities. 
Furthermore, even if the affected firms are known, the problem of how to correctly measure the externality remains. A simple before and after comparison of the performance of the firms neglects the other shocks that firms are exposed to and, more importantly, the issue of endogeneity: since mergers are a means of asset reallocation, they tend to occur in response to changes in the environment the firm operates in. Thus a naive before and after approach to measuring the merger's effect would confound the externality with the effect of the shock that initially triggered the merger. This can be accounted for by constructing an appropriate control group and using difference-in-difference (DiD) estimation. However, this generates another problem in turn: since the merger externality cannot reliably be confined to a specific set of firms, we cannot know with certainty which firms were not exposed to it. Thus, symmetrically to the problem of finding the firms which were affected, we face the problem of finding firms that were not affected to obtain an uncontaminated control group. In particular, since control observations should be as close as possible to the merging firms in dimensions such as product space, geographic space and time, it does not seem implausible that they would be affected by the merger as well. For these reasons identifying the externality of a merger on the relevant market has so far been elusive.

In this article we try to address the problems described and to provide empirical, crossindustry, estimates of merger externalities on the market. This is achieved through the use of a detailed and unique dataset of the market assessments by the European Commission (EC) in merger cases. The EC routinely publishes a competitive assessment and a delineation of the relevant markets in its decisions on notified mergers; we propose employing this information to circumvent the above problems as follows: the Commission's market investigation identifies the most important competitors in the product markets concerned by the merger, thus providing us with a set of firms that are most likely affected by the merger's externality. ${ }^{2}$ The Commission also assesses the extent of the relevant geographic market concerned by the merger. We exploit this information to construct a valid counterfactual by selecting control observations from outside the mergers' geographic scope.

This careful approach is important for a number of reasons: First, the use of correctly identified merger rivals and non-contaminated control groups permits us to provide the first causal estimates of the size of merger externalities in a cross-industry study. Secondly, by using separate control groups for merging firms and competitors, we ensure that our measurements are not confounded by the relative sizes of the efficiency and the market power effect. ${ }^{3}$ Finally and related to this point, we are able to distinguish the mergers' external effect from the effect on merger insiders, allowing us to draw conclusions relevant to competition policy.

Our findings are compatible with the predictions of Cournot and differentiated Bertrand competition: competitors grow faster than both the control group and the merging firms in the post-merger period, indicating a gain in market share at the expense of the merging firms. While the profitability of merging firms is lower after the acquisition, the competitors experience an increase of around one percentage point in their profit-to-assets ratio. This strongly suggests that in the average merger in our sample, the market power effect induced by the merger significantly

\footnotetext{
${ }^{2}$ Previous studies on the effect of mergers on rivals' prices were able to delineate the relevant market by focussing on industries characterized by many different local markets - e.g. hospitals (Dafny, 2009) or banks (Prager and Hannan, 1998) - such that some non-merging firms were merger rivals and some were not. This approach is not feasible in a cross-industry study.

${ }^{3}$ If, for example, the profitability of merging firms were to increase by two percentage points relative to their competitors after the merger, but a positive net externality (market power effect $>$ efficiency effect) increased rival profitability by one percentage point, the actual increase in the profitability of merging parties is three percentage points and our estimate would be biased downwards. Contrarily, in the presence of a negative externality on rivals we would overestimate the profitability effect on the merging parties.
} 
outweighs the efficiency effect. Additionally, we distinguish between industries with high and low elasticities of demand (as measured by firm profitability), as well as mergers between firms with high and low initial market shares, and again find the theoretical predictions corroborated: positive effects on rivals are higher if demand is less elastic or the pre-merger market shares are high.

The remainder of the article is structured as follows: section 2 discusses related empirical literature and presents the model, section 3 is concerned with the creation of the dataset, a number of methodological issues in the estimation of causal effects and our empirical approach. Results are presented in section 4 and section 5 concludes.

\section{Literature \& model}

\subsection{Related empirical literature}

There are a number of studies that use propensity score matching to create a credible counterfactual and DiD estimation to establish a causal effect in the evaluation of mergers: Ornaghi (2009) finds that large pharmaceutical firms decrease their R\&D activities after a merger, while Bertrand (2009) finds the opposite result for French manufacturing firms. Egger and Hahn (2010) find that Austrian banks significantly improve their cost performance after mergers.

While there is a large literature analyzing the direct effects of mergers on the insiders (e.g. Banerjee and Eckard (1998); Gugler et al. (2003); Mueller (1997) provides an overview), there are few studies that attempt to capture the impact on rivals. These studies either focus on the effect of the merger on market prices or the stock market performance of rivals.

The latter group was pioneered by two studies: Eckbo (1983) and Stillman (1983) look at the stock returns of rivals in horizontal mergers and find no evidence for anticompetitive effects. More recent studies use the reaction of rivals' stocks to distinguish pro- and anticompetitive mergers and evaluate the optimality of merger control decisions (Duso et al., 2007, 2011). They find that rivals accrue significant abnormal returns in response to a merger announcement (Clougherty and Duso, 2009), which is consistent with an increase in market power.

The effect of mergers on market prices is studied in the banking industry (Prager and Hannan, 1998; Focarelli and Panetta, 2003), the airline industry (Kim and Singal, 1993), the health care industry (Dafny, 2009) and various consumer product industries (Ashenfelter and Hosken, 2010). Using different methodological approaches, all these studies find some evidence for price increases after mergers in the industry. This points to a preponderance of market power effects over efficiency effects to the benefit of rivals.

It can, however, be argued that both strands of literature suffer from various shortcomings. Studies based on stock market data can only assess the markets' expectations about the effects on rivals, which do not need to be accurate, and they also strongly rely on the assumption that markets are informationally efficient. Critical perspectives on event-studies are provided by McAfee and Williams (1988) and Fridolfsson and Stennek (2005). The studies on price effects face other difficulties: for one, their conclusions are restricted to specific mergers or specific markets, and even on that scale it is hard to establish causality between the merger and the change in prices. Those studies that use control groups to mitigate this concern implicitly assume that the firms are not affected themselves.

This study aims to fill some of the gaps by (i) assessing the net externality of mergers on rivals based on reliable, ex-post measures in (ii) a large sample containing many different industries, using (iii) carefully constructed control groups in the estimation of causal effects. 


\subsection{A model à la Farrell and Shapiro (1990)}

In standard Cournot oligopoly models (Salant et al., 1983; Perry and Porter, 1985; Faulí-Oller, 1997) horizontal mergers are profitable for the merging firms only under rather specific circumstances. They are, however, always profitable for competitors, since - absent substantial efficiency gains - the merged entity will decrease its output, which increases the market price. In reaction, the competitors expand their output, but by a lesser amount than the insiders decrease their output, such that in the new equilibrium they sell a higher quantity at a higher price, which clearly is profitable. Farrell and Shapiro (1990) consider the possibility that the merged entity experiences efficiency gains through economies of scale or learning. Using simple Cournot examples, they show that these efficiency gains would have to be quite large to make the merger unprofitable for outsiders. In Bertrand oligopolies with differentiated products (Deneckere and Davidson, 1985) mergers are profitable for both insiders and outsiders, but again the free-riding outsiders benefit more than the merging firms. Thus from both kinds of standard IO oligopoly models (quantity competition and price competition with differentiated products), we would infer a positive externality on the profits of the rivals in the relevant market concerned by the merger, as long as no substantial efficiency gains are achieved.

To illustrate, assume an $n$-player, homogenous good Cournot oligopoly, with inverse demand given by $p(X)$ and each firm $i$ 's cost function given by $c_{i}\left(x_{i}\right)$, where $x_{i}$ denotes the output of firm $i, x_{-i}$ is the output of all other firms and $X=\sum_{i=1}^{n} x_{i}$ is market output. Each firm maximizes $\pi_{i}\left(x_{i}, x_{-i}\right)=p(X) x_{i}-c_{i}\left(x_{i}\right)$, which yields the first-order condition

$$
\frac{\partial \pi_{i}}{\partial x_{i}}=p(X)+x_{i} p^{\prime}(X)-c_{i}^{\prime}\left(x_{i}\right)=0 .
$$

Weighting (1) by market shares $s_{i}=\frac{x_{i}}{X}$ and summing over all firms we obtain

$$
\begin{aligned}
\sum_{i=1}^{n} s_{i} p(X)+p^{\prime}(X) \sum_{i=1}^{n} s_{i} x_{i}-\sum_{i=1}^{n} s_{i} c_{i}^{\prime} & =0 \Leftrightarrow \\
p(X)+\frac{p(X) p^{\prime}(X)}{p(X)} \sum_{i=1}^{n} s_{i}^{2} X & =c_{w}^{\prime} \Leftrightarrow \\
p(X)-\frac{p(X)}{\varepsilon} \sum_{i=1}^{n} s_{i}^{2} & =c_{w}^{\prime} \Leftrightarrow \\
p(X) & =\frac{c_{w}^{\prime}}{1-\frac{\mathrm{HHI}}{\varepsilon}}
\end{aligned}
$$

where $c_{w}^{\prime}=\sum_{i=1}^{n} s_{i} c_{i}^{\prime}$ is the weighted, average marginal cost, $\varepsilon=-\left(p^{\prime}(X) \frac{X}{p}\right)^{-1}$ is the absolute value of elasticity of demand and $\mathrm{HHI}=\sum_{i=1}^{n} s_{i}^{2}$ is the Herfindahl-Hirschmann index. Under mild assumptions, Farrell and Shapiro (1990) derive a necessary and sufficient condition for a merger to decrease equilibrium price or - equivalently - increase market output. In our context, this is equivalent to the pro-competitive externality exceeding the anti-competitive externality which is the case for two merging firms if and only if

$$
c_{M}^{\prime}\left(x_{1}+x_{2}\right)<p(X)\left(1-\frac{s_{1}+s_{2}}{\varepsilon}\right) .
$$

Thus the post-merger market price will be lower if the new marginal cost of the merged firms, $c_{M}^{\prime}$, at the combined pre-merger output level is lower than the pre-merger price times the term in brackets. If this condition is met, the pro-competitive externality of the merger 
outweighs the anti-competitive externality, such that the profits of rivals decrease. Inserting (2) into (3) tells us by how much the marginal cost of the merged entity has to decrease relative to the average marginal cost in the market for prices to decrease

$$
c_{M}^{\prime}\left(x_{1}+x_{2}\right)<c_{w}^{\prime}\left(\frac{1-\frac{s_{1}+s_{2}}{\varepsilon}}{1-\frac{\mathrm{HHI}}{\varepsilon}}\right)=c_{w}^{\prime}\left(\frac{\varepsilon-s_{1}-s_{2}}{\varepsilon-\mathrm{HHI}}\right)
$$

To illustrate, assume there are 10 symmetric firms $\left(s_{i}=.1\right)$, two of which merge. If demand is elastic at $\varepsilon=1.5$, then the marginal cost of the merged firm at the combined pre-merger output level would have to be less than $93 \%$ of the average marginal cost in the market for prices to fall. If demand is inelastic at $\varepsilon=.5$, this drops to $75 \%$. With five firms and market shares of $s_{i}=.2$, the threshold $c_{M}^{\prime}$ becomes $85 \%(\varepsilon=1.5)$ or $33 \%(\varepsilon=.5)$. Thus - in general - significant cost savings are required to make the transaction unprofitable for the other firms in the market.

Condition (4) is more easily met if the market shares of the merging parties are small and - given those shares - the industry is highly concentrated. The intuition for this is that if the initial market shares of the merging firms are small in spite of high market concentration, two formerly inefficient players become an effective rival and increase competition. For example, if in a market with four oligopolists $\left(s_{1}=s_{2}=.15, s_{3}=s_{4}=.35\right.$ and thus HHI=.29) firms 1 and 2 merge, the above rule suggests that the price will decrease as long as their new marginal cost is only slightly lower than the average marginal cost in the market. But given the low premerger market shares of firms 1 and 2, their pre-merger $c_{i}^{\prime}$ must have been very high, such that the required cost-savings for (4) to hold are still very high.

For the cases in our dataset where we can calculate the market share of both merging parties, the average market shares are $\overline{s_{1}}=.3, \overline{s_{2}}=.25$ and the average $\mathrm{HHI}$ is equal to .37 . With these values, marginal cost would have to decrease by $29 \%$ relative to average industry marginal cost for prices to fall if demand is unit elastic. Since there is no empirical, cross-industry evidence that mergers in general achieve even moderate efficiency gains ${ }^{4}$ and the size of the gains required to cancel the market-power externality is considerable, we expect that the anti-competitive externality will dominate on average, such that profitability and market shares of rivals increase after a merger.

By evaluating the effect of the parameters of market structure on the right-hand side term in brackets in (4), we obtain predictions on how they affect the likelihood of the price-decreasing condition being met. Deriving for either market share $s_{i}$ we obtain

$$
\partial\left(\frac{\varepsilon-s_{1}-s_{2}}{\varepsilon-\mathrm{HHI}}\right) / \partial s_{i}=-\frac{1}{\varepsilon-\mathrm{HHI}},
$$

which is almost certainly negative such that with larger pre-merger market shares marginal costs of merging firms would have to drop by more in order to decrease prices. ${ }^{5}$ This conforms to the intuition that firms that have market power in the first place are unlikely to engage in mergers that increase the competitive pressure in the industry to such a degree that the equilibrium price falls, unless enormous cost savings make this kind of behavior profitable. Thus mergers among firms with high market shares are more likely to exert a positive net externality on rival firms.

Empirically, we face the problem that due to data constraints market shares cannot always be calculated (particularly not for both merging firms) and, even if they can be, they are likely to

\footnotetext{
${ }^{4}$ For an industry study see Gugler and Siebert (2007).

$595 \%$ of the oligopolies in the sample have at least four firms, such that - assuming symmetry $-\varepsilon<0.25$ would be required for (5) to assume a positive sign. Most empirical studies of the elasticity of demand find significantly higher elasticities, even in markets for goods where one would expect a low elasticity, like cigarettes, electricity and medical services.
} 
exhibit a high degree of measurement error because they are based on the firms' overall sales and not on sales in the specific product market in question. We propose as proxy for market shares of the merging parties the number of competitors identified by the EC (i.e. including firms we do not have data on) and assume that market shares are higher if there are fewer competitors. This leads us to expect a larger externality on rivals if their number is small.

The derivative for the elasticity of demand,

$$
\partial\left(\frac{\varepsilon-s_{1}-s_{2}}{\varepsilon-\mathrm{HHI}}\right) / \partial \varepsilon=\frac{s_{1}+s_{2}-\mathrm{HHI}}{(\varepsilon-\mathrm{HHI})^{2}},
$$

will be positive in most cases, suggesting that price reductions are more likely in markets with a higher elasticity of demand, because a given price reduction will lead to a larger gain in market shares. If firms are symmetric, this will always be the case. Only if the merging firms are very small relative to the other firms, the sign might change. Because we do not directly observe the elasticities of demand in our sample, we use the average pre-merger profitability of acquirers to distinguish high- $\varepsilon$ and low- $\varepsilon$ markets: if the price elasticity of demand is low, firms will exploit this by setting higher prices and making higher profits; if it is high, firms will price more competitively and thus earn lower profits. Thus a mergers' positive impact on rivals should be more pronounced if initial profits are high.

\section{Data \& methodology}

In this section we describe how the dataset on competitors and merging firms was created, discuss the assumptions necessary to identify causal effects and try to establish their empirical validity in our approach to measuring the external effects of mergers.

\subsection{Constructing the dataset}

To construct the dataset, we combine merger-level information on 241 acquisitions that underwent the scrutiny of European competition law ${ }^{6}$ between 1990 and 2007, with firm-level information on the firms involved in these mergers. Roughly half the mergers in the sample were approved subject to conditions and obligations, while the other half was cleared unconditionally. Merger-level data was gathered from the official decisions of the European Commission, from which we collected the names of the merging firms and the most important rivals in the relevant product markets, as found in the market investigation, as well as the geographic size of the market affected by the merger. ${ }^{7}$ The firms thus identified were linked to balance-sheet data from the Thomson Reuters Worldscope database, providing data on income, sales, total assets, employees, debt, depreciation and market capitalization. Profitability is calculated as net income divided by total assets, Tobin's $q$ is the sum of market capitalization and total debt divided by total assets. All monetary variables are CPI-adjusted to 2005 USD and logarithmized.

After imposing all necessary restrictions on the data (firms have to be listed for firm-level data to be available; the relevant geographic market in the merger must not be worldwide; ${ }^{8}$

\footnotetext{
${ }^{6}$ The EC investigates mergers with a 'community dimension', defined as a set of financial thresholds. Details can be looked up at http://ec.europa.eu/competition/mergers/legislation/legislation.html.

${ }^{7}$ The EC's decisions on mergers are available at http://ec.europa.eu/competition/mergers/cases/.

${ }^{8}$ We compare firms in mergers with national or European-wide relevant geographic markets to firms outside of the market delineation. We drop worldwide mergers, because we cannot ensure that the control group would be unaffected by the merger. See appendix B for a robustness check including mergers in worldwide markets.
} 
observations where multiple mergers occur within the relevant timeframe are dropped; full firmlevel data on all variables mentioned above are required; top and bottom percentiles of the profitability variable are dropped) we obtain a sample of rivals and merging firms, which we complement with a large sample of almost 50,000 firms used for matching as described below.

Since after a merger, some (or all) of the target's business activities are added to the books of the acquirer, there is a surge in the acquiring firm's turnover between $t-1$ and $t+1$, where $t$ designates the period in which a merger ocurred. In our sample, we observe an average increase of more than a quarter in the sales of acquiring firms from $t-1$ to $t+1$. This consolidation effect is not a causal effect of the merger, but a bookkeeping phenomenon. To control for this, we construct a sample of consolidated entities by artificially consolidating the merging firms: we add up the sales, assets, income and other relevant variables of acquirer and target. To do this, we require full information on both the acquirer and the target in the same merger, resulting in a sample of 59 consolidated entities, the 'consolidated firm sample'. For these 59 mergers, we have data on 174 competitors identified by the EU Commission.

This is the ideal approach to study the effects of mergers; however, due to the high data requirements, we are left with a rather small sample. To broaden our analysis, we construct a second sample, the 'acquirer-only' sample, including all acquirers (130 firms) as well as all rivals identified for these 130 mergers (357 firms). ${ }^{9}$ By focussing on acquirers we make sure all the firms deciding to engage in an acquisition and are subject to its most immediate effects as well as their direct competitors are included. To avoid estimating an effect on sales that is due to the consolidation of the targets, we estimate the external and merger effect on sales in periods $t+2$ to $t+5$ relative to $t+1$ in this sample.

\subsection{Identifying the causal effect of treatment}

The estimation of causal treatment effects using DiD, matching or a combination of the two requires a set of assumptions on the composition of the treatment and control groups as well as on the nature of the treatment effect. Lechner (2010) identifies five necessary assumptions: the stable unit treatment value assumption (SUTVA), the exogeneity assumption (EXOG), the no-effect pre-treatment assumption (NEPT), the common trends assumption (CT) and the common support assumption (COSU), which will be discussed with regard to estimating merger externalities in the following.

SUTVA states that exactly one outcome (treatment or no treatment) is observed for each member of the population and that there are no relevant interactions between the groups. Letting $\delta_{i} \in\{0,1\}$ denote the treatment status of observation $i, j \in\{t-1, t+1\}$ denote the pre- and posttreatment periods, $Y_{i, j}$ denote $i$ 's observed outcome in $j$ and $Y_{j}^{d}$ denote the treatment and time specific, potential outcomes we can formally write SUTVA as:

$$
Y_{i, j}=\delta_{i} Y_{j}^{1}+\left(1-\delta_{i}\right) Y_{j}^{0}
$$

Thus, since $\delta_{i}$ is binary, only one of the potential outcomes is relevant for $i$ 's outcome; the outcomes do not interact. When applied to the context of externalities, SUTVA is violated by definition: the very effect we are looking for - the externality - contradicts the assumption of no relevant interactions between groups. It is therefore not possible to infer either the impact of the merger on the merging firms or the external effect on competitors by looking at just these two groups of firms (this was illustrated with an example in footnote 3). Even the use of an

\footnotetext{
${ }^{9}$ Actually, to estimate the effects of mergers on rival firms we do not need any information on the merging firms. Appendix A estimates the externalities using all available rival observations.
} 
industry-wide control group may not suffice to obtain unbiased estimates, as the control group could be affected as well. Particularly, the better (i.e. closer to the merging firms in terms of distance in physical and product space) the controls, the higher the probability of being affected.

EXOG, the assumption of exogeneity, requires that the observed distribution of covariates, $X$, does not depend on treatment status, i.e.:

$$
X=X^{1}=X^{0}
$$

This is not necessarily true for the merger treatment: when comparing non-merging firms with merging firms, the latter could be larger, more profitable or differ in other ways. While one could argue that being the recipient of an externality, i.e. a rival, is not a particularly distinguishing quality in itself, the EC's selection process for rivals might be. If the EU Commission identifies the most competitive rivals, rivals will be more efficient than the population of firms. Hence we cannot assume that EXOG holds ex-ante for either merging firms or competitors.

NEPT denotes the assumption, that there is no treatment effect in the pre-treatment period, thus excluding that anticipation of treatment influences the behaviour of individuals. This is very similar to the exogeneity assumption, with the focus shifted from covariates to the outcome variables. Letting $\theta_{j}\left(x_{i}\right)$ denote the treatment effect in $j$ for $X^{1}=x_{i}$, NEPT demands that

$$
\theta_{t-1}\left(x_{i}\right)=0 \quad \forall x_{i}
$$

Thus there should be no effect on profitability and sales in $t-1$ due to being a merging firm or a rival in the next period. While this seems plausible in the latter case (it seems unlikely that firms foresee being labeled a competitor by the EC and adjust their behaviour due to this), merging firms would typically know about their merger plans in advance and could act accordingly, or they could become merging firms in the first place because they earn high profits in previous periods, both of which would contradict NEPT.

The common trends assumption is central for the $\mathrm{DiD}$ approach and requires that except for the effect of treatment the control group faces the same time trends as the treatment group. This implies that in absence of treatment their expected evolution would have been the same:

$$
\begin{gathered}
E\left(Y_{t+1, i} \mid X=x_{i}, \delta_{i}=1\right)-E\left(Y_{t-1, i} \mid X=x_{i}, \delta_{i}=1\right)= \\
E\left(Y_{t+1, i} \mid X=x_{i}, \delta_{i}=0\right)-E\left(Y_{t-1, i} \mid X=x_{i}, \delta_{i}=0\right)
\end{gathered}
$$

This assumption would be violated if, for example, firms from sectors in which mergers occur are subjected to other trends than the control group. Since mergers are often triggered by sector-specific shocks (Fridolfsson and Stennek, 2005), this is not entirely implausible. Alternatively, changes in the political or legal framework could potentially favor or penalize merging firms vis-à-vis other firms.

Finally, since in this framework the identification of the causal effect relies on comparing treated and non-treated individuals in the pre- and post-treatment periods, COSU requires that observations are available in all four subsamples thus defined.

\subsection{Quantifying the externality}

This section describes the econometric methods employed to estimate the externalities and how they serve to address the concerns raised in the previous section. As discussed, the assumption that there are no relevant interactions between groups, SUTVA, is clearly violated between 
merging firms and their rivals. Furthermore, even the use of a control group may be problematic, because a well-matched control group may also be affected by the same merger. Thus we are looking for a valid control group, that is guaranteed not to be affected by the effects of the merger. This can be achieved by using control observations that are outside of the mergers' geographic scope as defined in the EC's market investigation. ${ }^{10}$ We therefore constrain the algorithm used in the construction of the control group to select control observations from a different nation if the geographic extent of the merger was found to be national and from a nonEuropean nation if the market was found to be Europe-wide. The strategy of selecting matches beyond the relevant geographic market of each merger should make sure that SUTVA holds.

Propensity-score matching is used to construct the control groups for merging firms and competitors: this is done by first estimating the determinants of receiving treatment and then choosing control observations that have similar ex-ante probabilities of receiving treatment. We estimate a probit model of the probability of being a competitor or an acquirer in period $t$ based on firm characteristics measured in period $t-1$, where $t$ ranges from 1990 to 2007. By using $t-1$ data, ${ }^{11}$ we make sure not to confound the determinants of a merger with its effects. ${ }^{12}$ The probability to be a competitor or an acquirer is modelled as a function of a set of firm-level covariates, meant to capture the relevant dimensions of firm performance.

To measure performance and size, profitability and sales are included; changes in the magnitude of these are our primary research interest and we therefore want to make certain that no significant ex-ante differences exist between treatment and control groups. The number of employees is intended to capture the firms' labour endowment. Depreciation is a proxy for the fixed costs of an industry. Finally, Tobin's $q$ is a measure of the stock market's assessment of the quality of a firm and its management. Additionally, we include a full set of 2-digit SIC dummies to make sure that the groups do not systematically differ with respect to their distribution across industries. Table 1 contains the results of the probit estimation. ${ }^{13}$

\section{Table 1 here}

The probability of being a relevant competitor increases with the amount of sales, the number of employees and with depreciation (column 1). While higher firm quality, as captured by Tobin's $q$, is also a significant determinant, profitability remains insignificant. The model also contains 39 2-digit SIC dummies (31 of them significant), which are not reported. We find similar results in the model for acquirers (column 2). Out of the 26 unreported industry dummies included, 23 are significant. ${ }^{14}$ The pseudo- $R^{2}$ values of 22 and 30 percent indicate, given the size of the dataset and the complex nature of the decision being modelled, a reasonably good fit of the models to the data.

As indicated by the coefficients of the probit model, competitors and merging firms differ from the average listed firm in various dimensions of firm performance. Column 1 of table 2

\footnotetext{
${ }^{10}$ Sometimes the EC provides different market sizes for different product markets. In these cases, the largest market definition was retained to ensure that controls are chosen from an unaffected area. As mentioned in footnote 8 , mergers with worldwide relevant markets are dropped from the main sample, but we discuss them in appendix B.

${ }^{11}$ The probit models were also estimated using $t-2$ and $t-3$ data, yielding similar results. However, the log-likelihood and goodness-of-fit measures favored the $t-1$ specification.

${ }^{12}$ For the same reason, the $t$ period is excluded from all estimations.

${ }^{13}$ Tables 1, 2 and 3, as well as figures 1, 2 and 3, i.e. the tables and figures documenting the creation and balancing of the dataset, all refer to the larger sample of acquirers. Results for the smaller consolidated firms sample, in which sample balance is more easily achieved, are very similar and not reported.

${ }^{14}$ The number of industry dummies differs between the models, because their coefficients can only be estimated if there are enough observations of acquirers or competitors in a particular industry. In both models, the maximum number of estimable industry dummies were included.
} 
contains the standardized biases ${ }^{15}$ before matching and shows that while not all covariates are significant determinants of being either a competitor or an acquirer, all of them do substantially differ between treated and non-treated firms. This means that in the initial sample the EXOG assumption is violated: clearly, the covariates are not independent of treatment status.

\section{Table 2 here}

After the probit models are estimated, we use their coefficients to predict the propensity score, i.e. the ex-ante probability of receiving treatment. This is the basis for matching: balancing the dataset with respect to the propensity score controls for selection on observables and produces a sample that is balanced with respect to the covariates included in the probit model. In addition to selecting control observations from beyond the mergers' relevant geographic market, we also impose a time constraint: by matching categorically on the year variable, we ensure that each control observation contains the same time period as the merger to which it is compared.

Thus, for every acquirer and every competitor in the sample, we select the best match in terms of their propensity score from the same year and outside of the relevant geographic market (1:1 matching without replacement). Column 2 of table 2 contains the remaining standardized biases and demonstrates that after the matching procedure most biases in the matched sample are below $2 \%$ and none are statistically significant. ${ }^{16}$ Furthermore, matching levels almost all differences in industry distribution. ${ }^{17}$ Figure 1 graphically shows the reduction in standardized bias achieved through matching, with sales, employees and depreciation on a logarithmized scale.

\section{Figure 1 here}

Table 2 and figure 1 demonstrate that the matching procedure successfully levels the differences in firm-level covariates. Since the covariates are now independent of treatment status, EXOG should hold in the matched sample. Also, since all control observations are selected from regions that are - as per the EC's appraisal - unaffected by the merger in question, we can be fairly certain that we can conclude that there are no relevant interactions between the groups and that SUTVA holds as well.

The matching algorithm was constrained such that each control observation refers to the same time-window as the corresponding treated observation and included a comprehensive set of industry dummies in the matching covariates. The CT assumption would be violated if macro trends differ between treated and control groups. Controlling for time and industries rules out that either external, time-dependent shocks or industry shocks systematically influence the results, but particularly merging firms could still react differently to changes in the political or legal framework. While there is no way to prove that CT holds, we graph the average, yearly growth rates of profitability and sales in all four subsamples and over the whole 1990 - 2009 period in figure 2 .

\section{Figure 2 here}

\footnotetext{
${ }^{15}$ The standardized bias $\left(\left(\bar{X}^{1}-\bar{X}^{0}\right) / \sigma^{1}\right.$, the difference in means of treated and control group divided by the standard deviation in the treatment group) is the bias one incurs by comparing treated to non-treated firms.

${ }^{16}$ The largest remaining bias (6\% bias in Tobin's $q$ in the competitor sample) is clearly insignificant at $p=0.45$.

${ }^{17}$ Initially, 31 out of 39 dummies in the rival model and 23 out of 26 dummies in the merging firms' model differ significantly between treatment and control group. After matching, only one dummy in the competitor sample remains significantly different at the $10 \%$ level.
} 
Figure 2 shows that changes in profitability and sales of merging firms, rivals and their respective control groups are highly correlated over the whole sample period. The correlations of the yearly average profitability growth of competitors and merging firms to their control groups are .90 and .78 respectively. The respective correlations for sales growth are .97 and .88 . This is a strong indication that macro trends are similar for all groups of firms.

Temporary, individual-specific shocks are well known from the evaluation of training programs for the unemployed: program participants typically experience a drop in wage - called Ashenfelter's dip after Ashenfelter (1978) - prior to program participation. In the context of mergers one could envision a scenario in which merging firms temporarily earn high windfall profits, e.g. due to some positive demand shock before the merger, use the profits to acquire another firm and return to a normal level of profits after either demand returns to its normal level or has been accomodated by an increase in supply. In both scenarios the assumption that treatment has no effect on the treated in the pre-treatment period, NEPT, is violated. To corroborate the validity of NEPT in our data, we graph profitability and sales data prior to a merger in figure 3 to check for systematic shocks on either group of firms.

\section{Figure 3 here}

The variation in profitability is less than one percentage point for both groups of firms in the eight years before a merger. Both groups expand their output in the pre-merger period and their sales growth moves in tandem. Thus we find no evidence for systematic, firm-specific shocks prior to treatment (violating NEPT). If both CT and NEPT are valid, unobserved firm-specific and time dependent heterogeneity is controlled for. Finally, COSU, the requirement that preand post-treatment observations have to be available for both the treated and the control group is fulfilled by construction. Summary statistics on all four groups in all periods of interest are reported in table 3 .

\section{Table 3 here}

Given that all necessary assumptions appear to be valid in the sample, we can proceed to estimate the causal effect of mergers on profitability and sales in a DiD framework. We implement the DiD setting by constructing a merger-timeline around the year in which a combination ocurred: $t$ designates the period in which a merger took place. Since matching occurs one year before the merger, treated and control firms do not significantly differ in the $t-1$ period. Therefore, we calculate the percentage point growth of the profitability of firm $i$ in periods $j=t+1, \ldots, t+5, \Delta \Pi_{i, j}$, with respect to $t-1$, create a set of dummy variables $\delta_{i, j}$ to indicate treatment status ( $\delta_{i, j}=1$ if $i$ was treated in $t$, otherwise 0$)$ and estimate the following equation

$$
\Delta \Pi_{i, j}=\alpha+\sum_{j=1}^{5} \delta_{i, j}+\varepsilon_{i, j} .
$$

Thus the coefficients of the dummies $\delta_{i, j}$ measure the differential in the growth path of profitability, $\Delta \Pi_{i, j}$, in period $j$ between the treatment and control groups, with reference to a point in time when the target variable did not significantly differ between groups, the $t-1$ period. We estimate the above equation in three subsamples: in the first subsample, only the rivals and their control group are included, such that the $\delta_{i, j}$ measure the profitability growth of rivals in excess of their control group. The second subsample only includes the merging firms 
and their control group. In these two estimation settings there is, as argued above, no reason to believe that SUTVA does not hold. In the third subsample, we drop all control observations and directly compare the performance of rivals and merging firms by letting the $\delta_{i, j}$ denote the incremental profitability growth in percentage points of rivals over merging firms. Here, SUTVA is violated and both the external and the merger effect are intermingled. We use these regressions as a check on our methodology. If the profitability growth of rivals exceeds that of their control groups while merging firms' profits are negatively affected, we would expect an even higher profitability growth differential when directly comparing the two groups. Conversely, if rival profits grow slower and merging firm profits grow faster, the direct comparison should reveal a more pronounced negative impact on rivals. If both groups are affected in a similar fashion, the direct comparison should partially or completely conceal the effect. The same logic applies to sales growth.

The effect on the growth of sales is estimated in almost the same setting with one difference: while the consolidation effect after a merger is accounted for by construction in the sample of consolidated firms, we have to correct for it in the sample including all acquirers, but where we lack the data on targets. Thus instead of calculating the growth of sales with respect to the $t-1$ period, we calculate it with respect to the $t+1$ period and report the $\delta_{i j}$ in periods two through five. ${ }^{18}$

\section{Results}

First we provide some preliminary findings by graphing the mean profitability and sales of merging firms and rivals over the post-merger period in both the acquirer (top panel) and the consolidated firms (bottom panel) samples, normalizing the $t-1$ values to one (figure 4 ). The average profitability of rivals initially decreases, but then increases to a considerably higher level in both samples: in periods $t+3$ to $t+5$ rivals are $20-25 \%$ (top panel) and 25-50\% (bottom panel) more profitable than in the periods before. Contrarily, the profitability of the merging firms is lower after the merger than before. Acquirers (consolidated entities) are, on average, $30 \%(14 \%)$ less profitable in the post-merger period.

The second column of figure 4 shows that the mean sales growth of acquirers and competitors is rather similar. The sales of consolidated firms, contrariwise, increase only by an average of $4.5 \%$ by period $t+5$, while those of their rivals increase by $27 \%$, indicating an increase in market shares at the expense of the consolidated firms.

\section{Figure 4 here}

Table 4 contains the regression results when estimating the post-merger sales growth of merging firms and rivals using robust regression techniques. When comparing the sales growth of merger rivals to the control group, we find no statistically significant difference in the first two years after the merger. Starting in $t+3$ in both samples, merger rivals significantly outgrow their control group: their cumulative sales growth exceeds that of the control group by 16 and 7 percentage points respectively in $t+5$, indicating a sizeable expansion of output during the observation period.

Contrarily, the sales growth of merging firms is lower than that of the control group in the consolidated firms sample during most of the observation period. While the coefficients are

\footnotetext{
${ }^{18}$ Neglecting this would lead us to believe that the merging firms strongly expanded their output in comparison to the control group and their rivals, while all we measure is just a consolidation effect.
} 
statistically significant in periods $t+1$ and $t+2$ only, their size suggests economic significance of the effect until four years after the merger. In the $t+5$ period the growth differential to the control group is closed. In the acquirer sample, all coefficients are insignificant.

Finally, when directly comparing the evolution of sales growth of merging firms and their rivals we find an unambiguous situation: rivals significantly outgrow the merging firms in the years after the acquisition. Given the positive growth dynamics of rivals and the growth slump of merging firms found in the previous regressions, this is hardly surprising. In both samples, the effect monotonically increases over the observation period and culminates in a growth differential of 8 percentage points in the acquirer sample and of 19 percentage points when using consolidated firms.

\section{Table 4 here}

The robust regression results for profitability are presented in table 5. The profitabilities of rivals and their controls are matched in $t-1$ and show no substantial discrepancy until $t+3$. Starting in $t+4$, the profitability of rivals exceeds that of the control group in the sample of consolidated firms. At the end of the observation period the change in rival profitability points to an economically and statistically significant external effect of about one percentage point in both samples.

Merging firms appear to be on average less profitable than the control group in the postmerger period. In the consolidated firms sample, the merging firms are less profitable in $t+1$ through $t+4$ by $0.5-1.1$ percentage points, but the effect is only statistically significant in $t+1$ and $t+2$. In the sample containing only acquirers the reduction of profitability is of similar size and significant in periods $t+1$ through $t+4$.

The direct comparison of rivals and merging firms reveals significant differences in profitability ranging between 1.3 and 1.6 percentage points in periods $t+4$ and $t+5$ in the sample of consolidated firms and between 0.7 and 1.9 percentage points in all post-merger periods in the acquirer sample. In this sample, SUTVA is violated and we perform a contaminated comparison. The fact that the negative effects on the merging firms reinforce the positive effects on rivals indicates that the results are not driven by the choice of control group.

\section{Table 5 here}

It thus seems that the merger paradox, i.e. the contention that mergers are more beneficial for outsiders than insiders, is supported by the data in our sample: horizontal mergers on average exert a positive externality on the profits and market shares of rival firms in the same market. ${ }^{19}$

We now examine the effect of market shares and the elasticity of demand on the size of the externality exerted by a merger: recall that from equations (5) and (6) we would expect a larger positive effect on rivals if market shares are high or the elasticity of demand is low. To identify markets with high initial market shares we use the median number of relevant competitors (equal to 7). ${ }^{20}$ Using the result that low demand elasticity entails high firm profits, we use the median pre-merger profitability of acquiring firms (equal to a return on assets of $3.7 \%$ ) to distinguish low- $\varepsilon$ and high- $\varepsilon$ markets. Table 6 contains the robust regression results in these subsamples. ${ }^{21}$

\footnotetext{
${ }^{19}$ Appendix D provides a robustness check differentiating firms according to their level of diversification.

${ }^{20}$ Appendix $\mathrm{C}$ uses the HHI for industries where we have sufficient data with consistent results.

${ }^{21}$ Results are based on the (larger) sample of acquiring firms, because further subdividing the - already small - sample of consolidated firms leaves us with few observations. However, all results reported below can be qualitatively replicated in the consolidated firms sample, with some reduced significances.
} 


\section{Table 6 here}

The first two columns of table 6 show that the externality on rival profits (measured visà-vis the control group) is larger in highly concentrated markets: while the coefficients in the high- $n$ subsample are mostly insignificant and only significantly positive at the $10 \%$ level in $t+5$, the coefficients obtained in the low- $n$ sample are larger and significant in all five evaluation periods. On average, the profit-to-assets ratio of rivals exceeds that of their control group by 1.1 percentage points in the years after a merger, if there are just a few firms in the market.

We find no significant externalities on rival profits if initial acquirer profits are low (column 3 ), because the elasticity of demand is high: market power effects are negligible if there are ample opportunities for substitution. If acquirers reap above-median profits because the elasticity of demand is low (column 4), the externality on rivals becomes much larger and signficant in three periods. Thus with a low elasticity of demand an increase in concentration entails higher firm profits in the sector.

\section{Conclusion}

This article attempts to empirically quantify the changes in firm performance brought about by a change in the structure of an oligopolistic market. The changes in market structure in our sample were due to horizontal mergers in the sector, i.e. a transition from an $n$ player oligopoly to an $n-1$ player oligopoly. These mergers were large enough to meet the notification criteria of the European Commission, which identifies the relevant competitors and the geographic extent of the market. We exploit this information by confining measurement to the identified competitors, which are directly affected by the merger, thus avoiding the bias toward zero incurred by including irrelevant firms. Furthermore, we use the geographic market definition as a delineation criterion for the choice of the control group.

Standard oligopoly models (i.e. Cournot competition or Bertrand competition with differentiated goods) predict that mergers mostly benefit the non-merging parties: while the merging firms reduce their combined output in order to raise the market price, competitors gain market shares. In the new equilibrium a higher market price prevails, resulting in higher profits for competitors. With quantity competition the merged entity will - except for very specific circumstances (Faulí-Oller, 1997) - earn less than before the merger. A profit-maximizing firm in such a market therefore has no incentive to merge, a fact that - when contrasted with the factual frequency of mergers - is often called the merger paradox.

Our results are consistent with these predictions: we find that rivals (non-merging firms that are active in the same product market) gain market shares and become significantly more profitable after an acquisition in the industry. At best, the sales and profits of the merging parties, on the other hand, stagnate during the post-merger evaluation period. The finding that rivals significantly profit from the reduction of players in the market suggests that the anti-competitive externality due to reduced competition in general outweighs the pro-competitive externality due to efficiency gains. We also derive predictions on the relationship of the size of the effect and the parameters of industry structure. Again we find theory corroborated by empirics: externalities on rivals are larger if industry concentration is high, if there are few competing firms and if the initial level of profits is high.

From the point of view of economic theory, our results can be regarded as a piece of evidence that the predictions of standard IO models appear to describe well the mechanics of real-world 
oligopoly markets. Alternatively, from the point of view of effective competition the mergers in the dataset appear to have been to the detriment of the consumers in the respective markets.

\section{References}

Ashenfelter, O., "Estimating the effect of training programs on earnings," The Review of Economics and Statistics, 1978, 60 (1), 47-57.

— and D. Hosken, "The effect of mergers on consumer prices: Evidence from five mergers on the enforcement margin," Journal of Law and Economics, 2010, 53 (3), 417-466.

Banerjee, Ajeyo and E. Woodrow Eckard, “Are Mega-Mergers Anticompetitive? Evidence from the First Great Merger Wave," The RAND Journal of Economics, 1998, 29 (4), 803-827.

Bertrand, Olivier, "Effects of foreign acquisitions on R\&D activity: Evidence from firm-level data for France," Research Policy, 2009, 38 (6), 1021-1031.

Clougherty, J.A. and T. Duso, “The impact of horizontal mergers on rivals: gains to being left outside a merger," Journal of Management Studies, 2009, 46 (8), 1365-1395.

Dafny, L., "Estimation and Identification of Merger Effects: An Application to Hospital Mergers," Journal of Law and Economics, 2009, 52 (3), 523-550.

Deneckere, R. and C. Davidson, "Incentives to form coalitions with Bertrand competition," The RAND Journal of Economics, 1985, 16 (4), 473-486.

Duso, T., K. Gugler, and B.B. Yurtoglu, "How effective is European merger control?," European Economic Review, 2011, 55 (7), 980-1006.

Duso, Tomaso, Damien J Neven, and Lars-Hendrik Röller, "The political economy of European merger control: evidence using stock market data," Journal of Law and Economics, 2007, 50 (3), 455-489.

Eckbo, B.E., "Horizontal mergers, collusion, and stockholder wealth," Journal of Financial Economics, 1983, 11 (1), 241-273.

Egger, Peter and Franz R Hahn, "Endogenous bank mergers and their impact on banking performance: Some evidence from Austria," International Journal of Industrial Organization, 2010, 28 (2), 155-166.

Farrell, J. and C. Shapiro, "Horizontal Mergers: An Equilibrium Analysis," The American Economic Review, 1990, 80 (1), 107-126.

Faulí-Oller, R., "On merger profitability in a Cournot setting," Economics Letters, 1997, 54 (1), $75-79$.

Focarelli, D. and F. Panetta, "Are mergers beneficial to consumers? Evidence from the market for bank deposits," The American Economic Review, 2003, 93 (4), 1152-1172.

Fridolfsson, S.O. and J. Stennek, "Why mergers reduce profits and raise share prices-A theory of preemptive mergers," Journal of the European Economic Association, 2005, 3 (5), 10831104. 
Gugler, K. and R. Siebert, "Market power versus efficiency effects of mergers and research joint ventures: evidence from the semiconductor industry," The Review of Economics and Statistics, 2007, 89 (4), 645-659.

_, D.C. Mueller, B.B. Yurtoglu, and C. Zulehner, "The effects of mergers: An international comparison," International Journal of Industrial Organization, 2003, 21 (5), 625-653.

Kim, E.H. and V. Singal, "Mergers and Market Power: Evidence from the Airline Industry," The American Economic Review, 1993, 83 (3), 549-569.

Lechner, M., "The Estimation of Causal Effects by Difference-in-Difference Methods," Foundations and Trends in Econometrics, 2010, 4 (3), 165-224.

McAfee, R Preston and Michael A Williams, "Can event studies detect anticompetitive mergers?," Economics Letters, 1988, 28 (2), 199-203.

Mueller, D.C., "Merger policy in the United States: A reconsideration," Review of Industrial Organization, 1997, 12 (5), 655-685.

Ornaghi, Carmine, "Mergers and innovation in big pharma," International Journal of Industrial Organization, 2009, 27 (1), 70-79.

Perry, M.K. and R.H. Porter, "Oligopoly and the incentive for horizontal merger," The American Economic Review, 1985, 75 (1), 219-227.

Prager, R.A. and T.H. Hannan, "Do substantial horizontal mergers generate significant price effects? Evidence from the banking industry," The Journal of Industrial Economics, 1998, 46 (4), 433-452.

Salant, S.W., S. Switzer, and R.J. Reynolds, "Losses from horizontal merger: the effects of an exogenous change in industry structure on Cournot-Nash equilibrium," The Quarterly Journal of Economics, 1983, 98 (2), 185-199.

Stillman, R., "Examining antitrust policy towards horizontal mergers," Journal of Financial Economics, 1983, 11 (1), 225-240. 


\section{Appendixes}

\section{A All rivals}

Since in our main specification we incur a possible selection bias by only evaluating the performance of rivals in cases for which we have data on the merging firms, we run a robustness check in a sample including as many rivals as possible: we retain all rival observations from all merger cases including those for which we lack data on the merging firms. This boosts the number of rivals included in the sample to 506, increasing the sample size by almost fifty percent.

In spite of this large variation in the sample, the results reported in table 7 are very similar to those obtained when comparing rivals to their control group in tables 4 and 5 in the acquirer-only sample.

\section{Table 7 here}

\section{B Worldwide mergers}

Table 8 contains the regression results when looking exclusively at mergers, where the relevant geographic market was found to be worldwide. Note that in this case SUTVA is violated. We now observe 32 acquiring firms and 137 competitors. There are no significant effects on the profitability of either group of firms. Examining the growth of sales we find that both rivals and merging firms expand their output faster than their control groups and find no significant difference when comparing them directly. These 'non-results' underline our approach of carefully accounting for the contamination of control groups.

\section{Table 8 here}

\section{Low and high HHI markets}

One of the predictions of the model presented in 2.2 is that the size of the externality on rivals increases with the initial market shares of the merging firms. Since actual market shares cannot be calculated in all cases and - even if they can be - are likely to be subject to significant measurement error, we use the number of competitors identified by the Commission as proxy in the main specification of the results. As a robustness check, we use an approximation to the industry HHI to distinguish markets with high and low market shares. Results are consistent with those reported in table 6.

Table 9 here

\section{Low and high number of product markets}

The model presented in section 2.2 assumes that firms are active in a single product market. However, our data include many large corporations that manufacture a multitude of products and are active in many markets at the same time. One would expect this to bias estimates downwards, 
since only a part of these firms' business is affected by a merger in a specific product market. To check whether this is the case, we count the number of 4-digit industry codes the firms report being active in, finding a median value of three. We re-estimate the merger externalities on profitability in a subsample of firms active in $\leq 3$ markets, where a larger effect is to be expected, and a subsample of more diversified firms active in more than 3 markets. The results in table 10 confirm these expectations: merger rivals with few products experience a sizeable, positive externality on their profitability in all five years after a merger, while the effects on more diversified rivals are weak. Similarly, merging firms are significantly less profitable by up to 2.7 percentage points in all evaluation periods if they have few products, but the effect is insignificant if they have many. The direct comparison of merging firms and rivals corroborates these findings. Thus our main findings, in a sample including both diversified and undiversified firms, can be seen as a lower bound for the effect on undiversified companies.

\section{Table 10 here}




\section{Tables \& figures}

Table 1: Propensity score estimation

\begin{tabular}{lcclc}
\hline \hline & \multicolumn{2}{c}{ Competitors } & \multicolumn{2}{c}{ Acquirers } \\
\hline Profitability & 0.123 & $(0.205)$ & 0.485 & $(0.516)$ \\
Sales & $0.122^{* * *}$ & $(0.030)$ & $0.111^{*}$ & $(0.058)$ \\
Employees & $0.102^{* * *}$ & $(0.025)$ & $0.187^{* * *}$ & $(0.045)$ \\
Depreciation & $0.065^{* *}$ & $(0.026)$ & $0.079^{*}$ & $(0.048)$ \\
Tobin's Q & $0.036^{* * *}$ & $(0.013)$ & $0.060^{* * *}$ & $(0.022)$ \\
\hline Observations & 354921 & 354921 \\
Pseudo $R^{2}$ & 0.221 & 0.295 \\
Industry dummies & \multicolumn{2}{c}{ yes } & \multicolumn{2}{c}{ yes } \\
Treated & 357 & \multicolumn{2}{c}{130} \\
\hline \hline
\end{tabular}

Notes: This table reports the results of the propensity score model. The dependent variables indicate whether the firm was a competitor (column 1) or an acquirer (column 2) in a merger case investigated by the EC in the following year. The independent variables are measures of firm size (sales, employees), fixed costs (depreciation) and performance (profitability, Tobin's $q$ ) and include the maximum amount of estimable 2-digit industry dummies (39 in the competitor model, 26 in the acquirer model). A common support is imposed. Standard errors in parentheses, ${ }^{*} \mathrm{p}<0.1,{ }^{* *}$ $\mathrm{p}<0.05,{ }^{* * *} \mathrm{p}<0.01$ 
Table 2: Standardized biases before and after matching

\begin{tabular}{lrc}
\hline \hline & Initial Bias (\%) & Remaining Bias (\%) \\
Competitors & & 1.87 \\
\hline Profitability & $36.22^{* * *}$ & 0.92 \\
Sales & $382.16^{* * *}$ & 1.09 \\
Employees & $460.53^{* * *}$ & 1.51 \\
Depreciation & $477.17^{* * *}$ & 6.01 \\
Tobin's Q & $56.93^{* * *}$ & \\
Acquirers & & 0.34 \\
\hline Profitability & $38.74^{* * *}$ & 1.18 \\
Sales & $611.77^{* * *}$ & 0.34 \\
Employees & $918.47^{* * *}$ & 1.74 \\
Depreciation & $841.24^{* * *}$ & 0.31 \\
Tobin's Q & $55.46^{* * *}$ & \\
\hline \hline
\end{tabular}

Notes: This table reports the standardized biases (calculated as $\left.\left(\bar{X}^{1}-\bar{X}^{0}\right) / \sigma^{1}\right)$ between treated and control groups. Initially (column 1 ), all firm-level covariates are significantly different at the $1 \%$ level between groups. After the matching procedure (column 2) all differences are insignificant. 

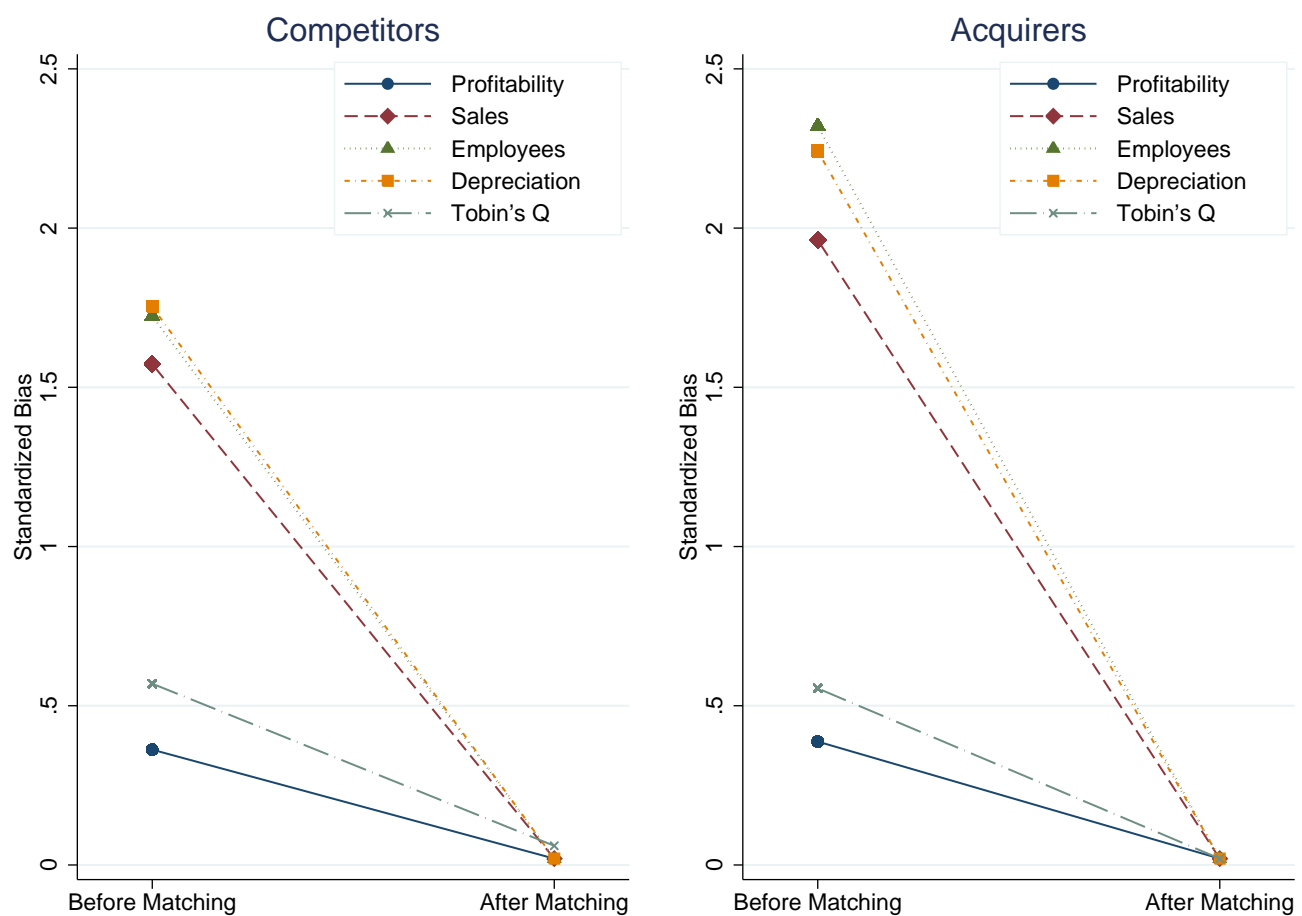

Figure 1: Standardized biases before and after matching 

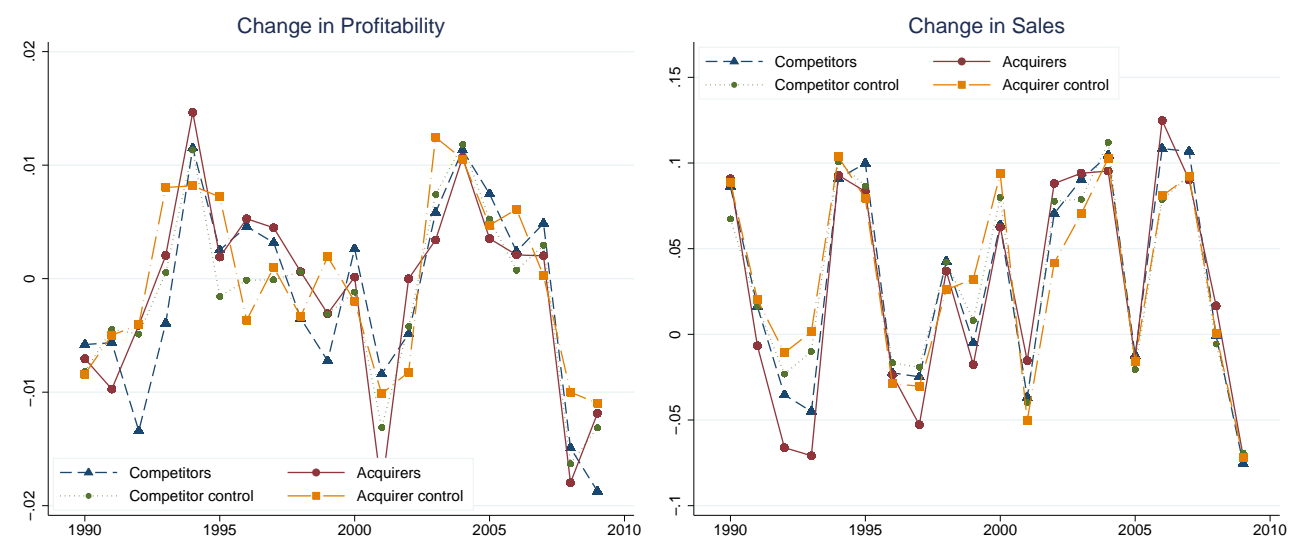

Figure 2: Yearly average change in profitability and sales 

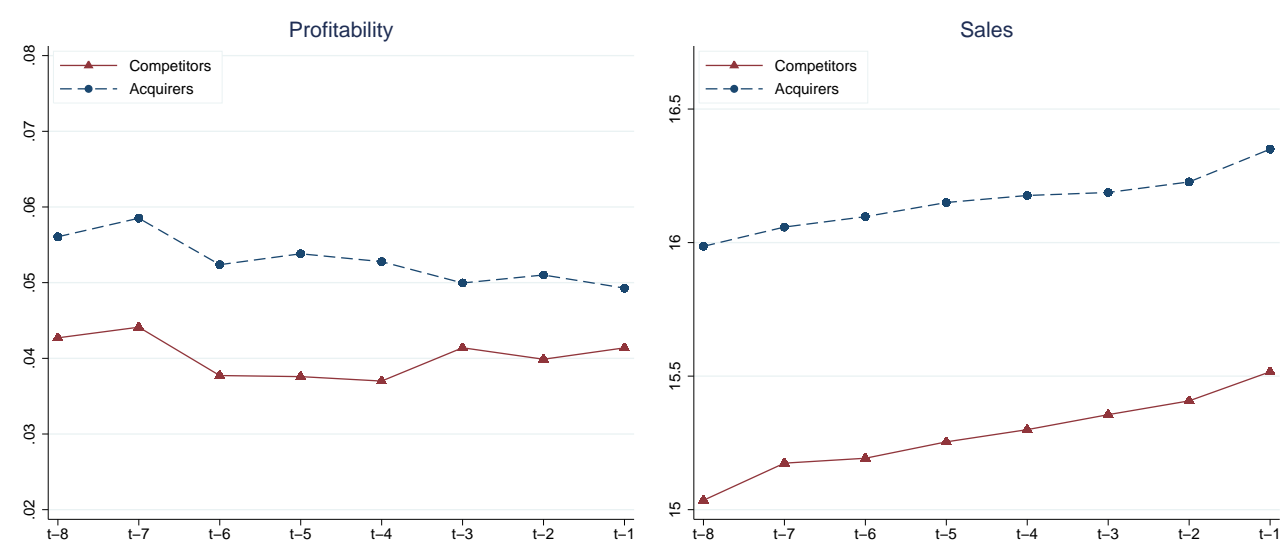

Figure 3: Evolution of profitability and sales in the pre-merger period 
Table 3: Summary statistics

\begin{tabular}{lcccccc} 
Competitors & $t-1$ & $t+1$ & $t+2$ & $t+3$ & $t+4$ & $t+5$ \\
\hline Profitability & 0.041 & 0.038 & 0.031 & 0.044 & 0.046 & 0.050 \\
$\ln ($ Sales) & 15.516 & 15.687 & 15.716 & 15.797 & 15.773 & 15.903 \\
$\ln$ (Total Assets) & 15.651 & 15.849 & 15.903 & 15.938 & 15.913 & 16.088 \\
$\ln ($ Employees) & 9.802 & 9.926 & 9.968 & 10.022 & 9.985 & 10.120 \\
Tobin's Q & 1.276 & 1.206 & 1.198 & 1.098 & 1.103 & 0.942 \\
\hline Observations & 357 & 357 & 357 & 353 & 300 & 274 \\
Control group & & & & & & \\
\hline Profitability & 0.043 & 0.043 & 0.047 & 0.048 & 0.043 & 0.039 \\
$\ln$ (Sales) & 15.491 & 15.594 & 15.612 & 15.647 & 15.678 & 15.627 \\
$\ln$ (Total Assets) & 15.538 & 15.679 & 15.725 & 15.789 & 15.817 & 15.767 \\
$\ln$ (Employees) & 9.824 & 9.929 & 9.946 & 9.958 & 9.917 & 9.915 \\
Tobin's Q & 1.299 & 1.111 & 1.017 & 0.895 & 0.791 & 0.730 \\
\hline Observations & 357 & 357 & 356 & 353 & 299 & 264 \\
\hline \hline
\end{tabular}

\begin{tabular}{lcccccc} 
Acquirers & $t-1$ & $t+1$ & $t+2$ & $t+3$ & $t+4$ & $t+5$ \\
\hline Profitability & 0.049 & 0.042 & 0.034 & 0.045 & 0.036 & 0.041 \\
$\ln$ (Sales) & 16.275 & 16.507 & 16.532 & 16.547 & 16.491 & 16.489 \\
$\ln$ (Total Assets) & 16.456 & 16.732 & 16.749 & 16.789 & 16.739 & 16.784 \\
$\ln$ (Employees) & 10.575 & 10.737 & 10.725 & 10.756 & 10.738 & 10.692 \\
Tobin's Q & 1.399 & 1.226 & 1.122 & 0.995 & 0.920 & 0.833 \\
\hline Observations & 130 & 130 & 130 & 130 & 118 & 110 \\
Control group & & & & & & \\
\hline Profitability & 0.048 & 0.042 & 0.041 & 0.036 & 0.031 & 0.038 \\
$\ln$ (Sales) & 16.305 & 16.421 & 16.458 & 16.529 & 16.385 & 16.557 \\
$\ln$ (Total Assets) & 16.411 & 16.543 & 16.575 & 16.628 & 16.635 & 16.660 \\
$\ln$ (Employees) & 10.568 & 10.624 & 10.652 & 10.669 & 10.646 & 10.660 \\
Tobin's Q & 1.395 & 1.138 & 1.009 & 0.852 & 0.765 & 0.699 \\
\hline Observations & 130 & 130 & 129 & 129 & 112 & 107 \\
\hline \hline
\end{tabular}

Notes: This table reports the mean values of firm-level covariates in the matching period $(t-1)$ and the five evaluation periods $([t+1, t+5])$ for competitors, acquirers and their respective control groups. Sample size decreases over time due to data constraints. See text for variable definitions. 

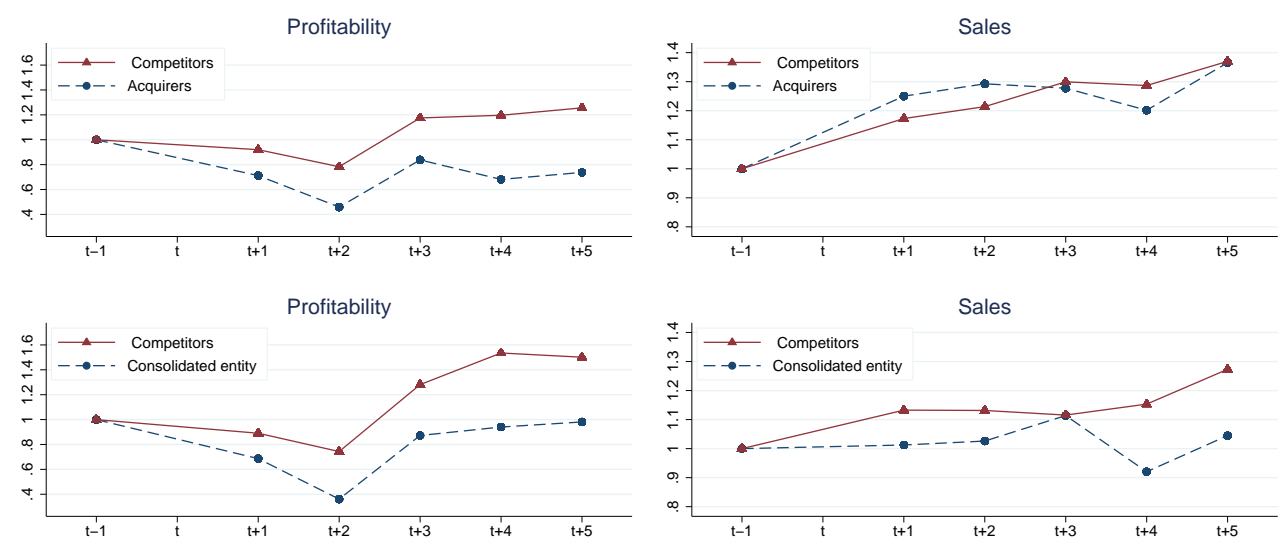

Figure 4: Evolution of profitability and sales in the post-merger period 
Table 4: Main results: Sales

\begin{tabular}{|c|c|c|c|c|c|c|}
\hline \multicolumn{7}{|c|}{ Consolidated firms sample } \\
\hline & \multicolumn{2}{|c|}{ Rivals vs. controls } & \multicolumn{2}{|c|}{ Merging vs. controls } & \multicolumn{2}{|c|}{ Rivals vs. merging } \\
\hline$t+1$ & -0.017 & $(0.029)$ & $-0.109^{* *}$ & $(0.045)$ & 0.034 & $(0.034)$ \\
\hline $\mathrm{t}+2$ & -0.003 & $(0.029)$ & $-0.109^{* *}$ & $(0.045)$ & 0.055 & $(0.034)$ \\
\hline$t+3$ & $0.062^{* *}$ & $(0.031)$ & -0.046 & $(0.049)$ & $0.103^{* * *}$ & $(0.035)$ \\
\hline $\mathrm{t}+4$ & $0.119^{* * *}$ & $(0.033)$ & -0.073 & $(0.051)$ & $0.154^{* * *}$ & $(0.036)$ \\
\hline $\mathrm{t}+5$ & $0.163^{* * *}$ & $(0.034)$ & 0.000 & $(0.054)$ & $0.190^{* * *}$ & $(0.038)$ \\
\hline Obs. & 1388 & & 461 & & 913 & \\
\hline \multicolumn{7}{|c|}{ Acquirer-only sample } \\
\hline & \multicolumn{2}{|c|}{ Rivals vs. controls } & \multicolumn{2}{|c|}{ Merging vs. controls } & \multicolumn{2}{|c|}{ Rivals vs. merging } \\
\hline $\mathrm{t}+1$ & -0.015 & $(0.020)$ & & & & \\
\hline $\mathrm{t}+2$ & -0.001 & $(0.020)$ & -0.019 & $(0.022)$ & -0.017 & $(0.017)$ \\
\hline$t+3$ & $0.043^{* *}$ & $(0.021)$ & -0.007 & $(0.023)$ & 0.025 & $(0.018)$ \\
\hline $\mathrm{t}+4$ & $0.057^{* *}$ & $(0.022)$ & -0.013 & $(0.024)$ & $0.045^{* *}$ & (0.019) \\
\hline$t+5$ & $0.067^{* * *}$ & $(0.024)$ & 0.011 & $(0.026)$ & $0.076^{* * *}$ & $(0.020)$ \\
\hline Obs. & 2771 & & 823 & & 1403 & \\
\hline
\end{tabular}

Notes: This table reports the DiD estimation results of the change in sales in the evaluation period. Column 1 compares rivals to their control group, column 2 compares merging firms to their control group and column 3 directly compares rivals and merging firms. Results are reported for the sample of consolidated firm (upper panel) and the sample containing all acquiring firms (lower panel). In the latter sample, no coefficients are estimated for the $t+1$ period to avoid measuring the consolidation effect (see text); instead, the other coefficients are estimated relative to $t+1$. Standard errors in parentheses, ${ }^{*} \mathrm{p}<0.1,{ }^{* *} \mathrm{p}<0.05,{ }^{* * *} \mathrm{p}<0.01$ 
Table 5: Main results: Profitability

\begin{tabular}{|c|c|c|c|c|c|c|}
\hline \multicolumn{7}{|c|}{ Consolidated firms sample } \\
\hline & \multicolumn{2}{|c|}{ Rivals vs. controls } & \multicolumn{2}{|c|}{ Merging vs. controls } & \multicolumn{2}{|c|}{ Rivals vs. merging } \\
\hline$t+1$ & -0.004 & $(0.004)$ & $-0.011^{* *}$ & $(0.006)$ & 0.001 & $(0.005)$ \\
\hline$t+2$ & -0.005 & $(0.004)$ & $-0.011^{*}$ & $(0.006)$ & 0.002 & $(0.005)$ \\
\hline$t+3$ & 0.003 & $(0.004)$ & -0.005 & $(0.006)$ & 0.008 & $(0.005)$ \\
\hline$t+4$ & $0.010^{* *}$ & $(0.005)$ & -0.008 & $(0.006)$ & $0.016^{* * *}$ & $(0.005)$ \\
\hline$t+5$ & $0.009^{*}$ & $(0.005)$ & 0.003 & $(0.007)$ & $0.013^{* *}$ & $(0.005)$ \\
\hline Obs. & 1380 & & 462 & & 908 & \\
\hline \multicolumn{7}{|c|}{ Acquirer-only sample } \\
\hline & \multicolumn{2}{|c|}{ Rivals vs. controls } & \multicolumn{2}{|c|}{ Merging vs. controls } & \multicolumn{2}{|c|}{ Rivals vs. merging } \\
\hline$t+1$ & -0.000 & $(0.003)$ & $-0.009^{* *}$ & $(0.004)$ & $0.009^{* * *}$ & $(0.003)$ \\
\hline$t+2$ & -0.002 & $(0.003)$ & $-0.009^{* *}$ & $(0.004)$ & $0.007^{*}$ & $(0.003)$ \\
\hline$t+3$ & 0.003 & $(0.003)$ & $-0.009^{* *}$ & $(0.005)$ & $0.013^{* * *}$ & $(0.004)$ \\
\hline$t+4$ & 0.002 & $(0.003)$ & $-0.010^{* *}$ & $(0.005)$ & $0.012^{* * *}$ & $(0.004)$ \\
\hline$t+5$ & $0.008^{* *}$ & $(0.003)$ & -0.007 & $(0.005)$ & $0.019^{* * *}$ & $(0.004)$ \\
\hline Obs. & 2748 & & 1068 & & 1826 & \\
\hline
\end{tabular}

Notes: This table reports the $\mathrm{DiD}$ estimation results of the change in profitability in the evaluation period. Column 1 compares rivals to their control group, column 2 compares merging firms to their control group and column 3 directly compares rivals and merging firms. Results are reported for the sample of consolidated firm (upper panel) and the sample containing all acquiring firms (lower panel). Standard errors in parentheses, ${ }^{*} \mathrm{p}<0.1,{ }^{* *} \mathrm{p}<0.05,{ }^{* * *} \mathrm{p}<0.01$ 
Table 6: Externalities on rival profitability and market characteristics

\begin{tabular}{ccccc}
\hline \hline & Low $n$ & High $n$ & Low $\Pi_{m}$ & High $\Pi_{m}$ \\
\hline $\mathrm{t}+1$ & $0.007^{*}$ & 0.002 & -0.006 & $0.006^{*}$ \\
& $(0.004)$ & $(0.004)$ & $(0.004)$ & $(0.003)$ \\
$\mathrm{t}+2$ & $0.008^{*}$ & -0.003 & -0.006 & 0.003 \\
& $(0.004)$ & $(0.004)$ & $(0.004)$ & $(0.004)$ \\
$\mathrm{t}+3$ & $0.012^{* * *}$ & 0.004 & -0.003 & $0.010^{* * *}$ \\
& $(0.004)$ & $(0.004)$ & $(0.004)$ & $(0.004)$ \\
$\mathrm{t}+4$ & $0.012^{* * *}$ & 0.003 & -0.000 & 0.005 \\
& $(0.004)$ & $(0.004)$ & $(0.004)$ & $(0.004)$ \\
$\mathrm{t}+5$ & $0.016^{* * *}$ & $0.009^{*}$ & 0.006 & $0.013^{* * *}$ \\
& $(0.004)$ & $(0.005)$ & $(0.005)$ & $(0.005)$ \\
\hline Obs. & 1332 & 1631 & 1257 & 1743 \\
\hline \hline
\end{tabular}

Notes: This table reports the DiD estimation results of the change in profitability of rival firms relative to their control group. Column 1 estimates the effect in the subsample of cases where the EC identified fewer than seven competitors; column 2 is the subsample of cases where seven or more competitors were identified. Column 3 reports the estimates in the subsample in which the pre-merger profitability of acquirers is lower than its median of $3.7 \%$, in column 4 it is higher. Standard errors in parentheses, ${ }^{*} \mathrm{p}<0.1,{ }^{* *} \mathrm{p}<0.05,{ }^{* * *} \mathrm{p}<0.01$ 
Table 7: All rival firms

\begin{tabular}{lccll}
\hline \hline & \multicolumn{2}{c}{ Rival profitability } & \multicolumn{2}{c}{ Rival sales } \\
\hline $\mathrm{t}+1$ & -0.001 & $(0.002)$ & 0.001 & $(0.018)$ \\
$\mathrm{t}+2$ & -0.001 & $(0.002)$ & 0.018 & $(0.018)$ \\
$\mathrm{t}+3$ & 0.002 & $(0.002)$ & $0.059^{* * *}$ & $(0.019)$ \\
$\mathrm{t}+4$ & 0.002 & $(0.003)$ & $0.072^{* * *}$ & $(0.020)$ \\
$\mathrm{t}+5$ & $0.006^{* *}$ & $(0.003)$ & $0.111^{* * *}$ & $(0.022)$ \\
\hline Obs. & 4026 & & 4059 &
\end{tabular}

Notes: This table reports the differences in profitability and sales growth of rival firms compared to their control group, when including all available rival firms (instead of only those in cases, where data on the merging firms is available as well). Standard errors in parentheses, ${ }^{*} \mathrm{p}<0.1,{ }^{* *} \mathrm{p}<0.05,{ }^{* * *} \mathrm{p}<0.01$ 
Table 8: Results for worldwide relevant markets; acquirers only

\begin{tabular}{|c|c|c|c|c|c|c|}
\hline \multicolumn{7}{|c|}{ Profitability } \\
\hline & \multicolumn{2}{|c|}{ Rivals vs. controls } & \multicolumn{2}{|c|}{ Merging vs. controls } & \multicolumn{2}{|c|}{ Rivals vs. merging } \\
\hline$t+1$ & 0.003 & $(0.004)$ & -0.001 & $(0.009)$ & 0.003 & $(0.005)$ \\
\hline$t+2$ & -0.000 & $(0.004)$ & -0.005 & $(0.009)$ & 0.001 & $(0.005)$ \\
\hline$t+3$ & -0.003 & $(0.005)$ & -0.009 & $(0.010)$ & -0.003 & $(0.005)$ \\
\hline $\mathrm{t}+4$ & 0.006 & $(0.005)$ & -0.007 & $(0.010)$ & 0.005 & $(0.006)$ \\
\hline $\mathrm{t}+5$ & 0.002 & $(0.005)$ & -0.002 & $(0.011)$ & 0.002 & $(0.006)$ \\
\hline Obs. & 1075 & & 268 & & 679 & \\
\hline \multicolumn{7}{|l|}{ Sales } \\
\hline & \multicolumn{2}{|c|}{ Rivals vs. controls } & \multicolumn{2}{|c|}{ Merging vs. controls } & \multicolumn{2}{|c|}{ Rivals vs. merging } \\
\hline$t+1$ & -0.018 & $(0.037)$ & & & & \\
\hline $\mathrm{t}+2$ & 0.021 & $(0.038)$ & -0.036 & $(0.049)$ & -0.071 & $(0.044)$ \\
\hline $\mathrm{t}+3$ & 0.025 & $(0.040)$ & -0.026 & $(0.051)$ & -0.073 & $(0.046)$ \\
\hline $\mathrm{t}+4$ & $0.079^{*}$ & $(0.043)$ & $0.093^{*}$ & $(0.054)$ & -0.021 & $(0.049)$ \\
\hline $\mathrm{t}+5$ & $0.126^{* * *}$ & $(0.045)$ & $0.123^{* *}$ & $(0.056)$ & 0.028 & $(0.051)$ \\
\hline Obs. & 1087 & & 206 & & 684 & \\
\hline
\end{tabular}

Notes: This table reports the DiD estimation results of the changes in the profitability and sales of merging and rival firms, when analysis is restricted to mergers with worldwide relevant markets, violating the SUTVA assumption (section 3.2). Standard errors in parentheses, ${ }^{*} \mathrm{p}<0.1,{ }^{* *} \mathrm{p}<0.05,{ }^{* * *} \mathrm{p}<0.01$ 
Table 9: Rival profitability and HHI

\begin{tabular}{ccccc}
\hline \hline & \multicolumn{2}{c}{ Low HHI } & \multicolumn{2}{c}{ High HHI } \\
\hline $\mathrm{t}+1$ & -0.003 & $(0.004)$ & 0.003 & $(0.004)$ \\
$\mathrm{t}+2$ & $-0.007^{*}$ & $(0.004)$ & 0.006 & $(0.005)$ \\
$\mathrm{t}+3$ & -0.005 & $(0.004)$ & $0.009^{* *}$ & $(0.005)$ \\
$\mathrm{t}+4$ & -0.006 & $(0.004)$ & $0.012^{* *}$ & $(0.005)$ \\
$\mathrm{t}+5$ & 0.003 & $(0.005)$ & $0.011^{* *}$ & $(0.005)$ \\
\hline Obs. & 1418 & & 806 &
\end{tabular}

Notes: This table reports the $\mathrm{DiD}$ estimation results of the change in profitability of rival firms relative to their control group. Column 1 estimates the effect in the subsample of cases where the approximated $\mathrm{HHI}$ index is lower than its median values of .37, in column 2 the $\mathrm{HHI}$ is above its median. Standard errors in parentheses, * $\mathrm{p}<0.1,{ }^{* *} \mathrm{p}<0.05,{ }^{* * *} \mathrm{p}<0.01$ 
Table 10: Profitability effects on few- and multi-product firms

\begin{tabular}{|c|c|c|c|c|c|c|}
\hline & \multicolumn{3}{|c|}{ Few product firms } & \multicolumn{3}{|c|}{ Multi product firms } \\
\hline & Rivals & Merging & Rivals vs. merging & Rivals & Merging & Rivals vs. merging \\
\hline \multirow[t]{2}{*}{$t+1$} & $0.006^{*}$ & $-0.022^{* * *}$ & $0.017^{* * *}$ & -0.001 & 0.004 & -0.002 \\
\hline & $(0.004)$ & $(0.007)$ & $(0.005)$ & $(0.003)$ & $(0.006)$ & $(0.004)$ \\
\hline \multirow[t]{2}{*}{$t+2$} & $0.006^{*}$ & $-0.021^{* * *}$ & $0.018^{* * *}$ & -0.001 & 0.003 & -0.003 \\
\hline & $(0.004)$ & $(0.007)$ & $(0.005)$ & $(0.003)$ & $(0.006)$ & $(0.004)$ \\
\hline \multirow[t]{2}{*}{$t+3$} & $0.010^{* * *}$ & $-0.017^{* *}$ & $0.022^{* * *}$ & 0.001 & -0.001 & 0.001 \\
\hline & $(0.004)$ & $(0.007)$ & $(0.005)$ & $(0.003)$ & $(0.006)$ & $(0.004)$ \\
\hline \multirow[t]{2}{*}{$t+4$} & $0.008^{* *}$ & $-0.026^{* * *}$ & $0.020^{* * *}$ & 0.002 & 0.003 & 0.001 \\
\hline & $(0.004)$ & $(0.007)$ & $(0.005)$ & $(0.003)$ & $(0.007)$ & $(0.004)$ \\
\hline \multirow[t]{2}{*}{$t+5$} & $0.015^{* * *}$ & $-0.027^{* * *}$ & $0.027^{* * *}$ & $0.007^{*}$ & 0.011 & $0.007^{*}$ \\
\hline & $(0.005)$ & $(0.008)$ & $(0.006)$ & $(0.004)$ & $(0.007)$ & $(0.004)$ \\
\hline Obs. & 1918 & 549 & 1200 & 1655 & 522 & 983 \\
\hline
\end{tabular}

Notes: This table reports the DiD results of the change in profitability, when estimation is restricted to firms reporting less than or equal to the median (equal to three) of 4-digit industry codes (columns $1-3$ ) and firms reporting more than the median (columns 4 - 6). Standard errors in parentheses, ${ }^{*} \mathrm{p}<0.1,{ }^{* *} \mathrm{p}<0.05,{ }^{* * *} \mathrm{p}<0.01$ 